
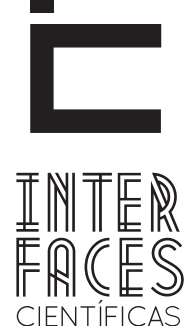

EDUCAÇÃO

ISSN IMPRESSO 2316-333X

ISSN ELETRÔNICO 2316-3828

Artigos de demanda contínua

\title{
AS NOVAS QUESTÕES DA LINGUÍSTICA APLICADA PARA O ENSINO DE LÍNGUA INGLESA: MULTILETRAMENTOS, IDENTIDADE E CULTURA
}

Rodrigo Belfort Gomes ${ }^{1}$

\section{RESUMO}

A linguística aplicada, como afirma Almeida Filho (2007), Moita Lopes (2006) e Rajagopalan (2006), está preocupada com todos os aspectos que envolvem o ensino de línguas, o que fez com que o objetivo do professor de idiomas e estudiosos desse campo, fosse, por muito tempo, a busca pelo melhor método a ser empregado. Essas questões, no entanto, vêm sendo modificadas com o desenvolvimento da linguística crítica, que agregou ao professor um papel de formador de cidadãos, não sendo suficiente apenas ensinar o idioma. É objetivo deste artigo, fazer um levantamento sobre os principais métodos e abordagens utilizados para o ensino de língua estrangeira, mais especificamente de língua inglesa, destacando os seus objetivos educacionais. Após esse levantamento inicial, foi feita uma análise sobre o papel do professor em sala de aula, que, diante deste novo cenário educacional, precisa conciliar os conhecimentos linguísticos que serão transmitidos com as novas discussões da linguística aplicada sobre as teorias de multiletramentos, as questões culturais e o processo de (re) construção identitária, possibilitados a partir do trabalho textual.

\section{PALAVRAS-CHAVE}

Cultura. Identidade. Linguística Aplicada. Multiletramentos. 


\section{ABSTRACT}

The applied linguistics, as stated by Almeida Filho (2007), Moita Lopes (2006) and Rajagopalan (2006), is concerned with all aspects involving the language teaching, so the search for the best method to use was the goal of language teachers and scholars for a long time. However, these issues have been modified with the development of linguistic criticism, which added to the teacher the role of a citizen maker, thus it is not enough just to teach the language. It is the aim of this article, to make a survey of the main methods and approaches used for teaching foreign languages, specifically English, highlighting their educational goals. After this initial survey, an analysis of the role of the teacher in the classroom was made, because this professional, facing this new educational scenario, needs to reconcile the language skills that will be transmitted to new discussions of applied linguistics on the theories of multiliteracies, cultural issues and the (re) construction, made possible from the work with texts.

\section{KEYWORDS}

Culture. Applied Linguistics. Identity. Multiliteracies.

\section{RESUMEN}

La lingüística aplicada, como dijo Almeida Filho ( 2007 ), Moita Lopes (2006) y Rajagopalan ( 2006 ), se ocupa de todos los aspectos que implica la enseñanza de las lenguas, lo que ha hecho que el objetivo de un profesor de lengua y estudiosos de ese campo, fuera durante mucho tiempo, la búsqueda del mejor método a utilizar. Estas cuestiones, sin embargo, han sido modificadas con el desarrollo de la lingüística crítica, que agregó al profesor el papel de la formación de los ciudadanos, no siendo suficiente tan sólo enseñar el idioma. Es el objeto de este artículo, hacer un estudio de los principales métodos y enfoques utilizados para la enseñanza de lenguas extranjeras, especialmente el idioma Inglés, destacando sus metas educativas. Después de este estudio inicial, ha sido hecho un análisis del papel del profesor en el aula, y se concluye que, ante este nuevo escenario educativo, hay ahora la necesidad de conciliar las habilidades lingüísticas que se transmitirán, a las nuevas discusiones sobre las teorías lingüísticas aplicadas de multialfabetizaciones y a las cuestiones culturales y a los procesos de construcción que se hizo posible a partir del trabajo textual.

\section{Palabras-clave}

Cultura. Identidad. Lingüística Aplicada. Multialfabetizaciones. 
0 processo de ensino-aprendizagem de língua inglesa ficou, por muito tempo, restrito a discussões sobre métodos de ensino, enquanto que as questões reflexivas ficavam em segundo plano, já que se pensava que não havia nenhum ganho em termos de conhecimento assimilado. Com o avanço dos estudos da linguística aplicada, percebeu-se a necessidade em extrapolar os conhecimentos gramaticais e lexicais, tão fortemente explorados pelo professor, e intensificar os questionamentos levantados em sala de aula, de forma que a criticidade do aluno fosse trabalhada, e auxiliasse na sua construção de ser social crítico, que vive em um mundo globalizado. 0 início desse processo se dá por meio das atividades de leitura, que devem ser trabalhadas de forma a possibilitar uma identificação do aluno com o texto e uma (re) significação identitária.

Resgatando os anseios iniciais da linguística aplicada, quatro métodos podem ser elencados por terem sido significantes para o ensino de língua estrangeira, em especial, da língua inglesa.

Também chamado de método clássico, o grammar translation (gramática e tradução) ganhou força no século XX, propondo um ensino de inglês baseado apenas na memorização de palavras, tradução de textos e emprego de regras gramaticais em frases isoladas. Mesmo com o surgimento de outros métodos, como o audiolingual e o método direto, o grammar translation não perdeu força no ensino, especialmente nas escolas de ensino fundamental e médio no Brasil, privilegiando, segundo Larsen-Freeman (2000), um ensino descontextualizado, e, por vezes, enfadonho.

De acordo com Larsen-Freeman (2000), o propósito primeiro da aprendizagem de um idioma deve ser a comunicação, e, para atingir esse objetivo, o método direto preconizava a total exclusão da língua materna nas salas de aula e a introdução de atividades conversacionais. A aula precisava ser ensinada estritamente na língua alvo, sem nenhum tipo de tradução. Todo o ensino se dava a partir da leitura de pequenos textos e do trabalho oral desenvolvido a partir de uma série de perguntas e respostas que, extensivamente, cobriam todo o texto lido. Apesar da inovação em promover um ensino na língua alvo, o método direto deixava certa angústia nos aprendizes, já que o ensino da gramática era colocado como dispensável e o uso da língua materna era totalmente proibido em sala de aula.

No período pós-guerra, o método Áudio-lingual é desenvolvido nos EUA, tendo como principal objetivo, de acordo com Larsen-Freeman (2000), atender a questões militares, na medida em que era do interesse do governo que seu exército aprendesse a se comunicar oralmente em língua estrangeira o mais rápido possível. De acordo com esse método, o aprendizado era garantido por meio de técnicas de repetição, utilizando-se, para tanto, laboratórios de línguas que possibilitassem aos alunos entrar em contato com material auditivo gravado com diálogos de nativos da língua inglesa. Acreditava-se que uma língua estrangeira poderia ser facilmente aprendida por meio do condicionamento e da formação de hábitos. 0 uso da língua materna era novamente condenado nesse método, que via a língua inglesa não como uma fonte de tópicos a serem discutidos, e sim de frases a serem memorizadas, uma vez que "learners could overcome the habits of their native language and form the new habits required to be target language speakers" 2 (LARSEN-FREEMAN, 2000, p. 35).

Com o surgimento da abordagem comunicativa, na segunda metade do século $X X$, as preocupações com aulas de línguas desinteressantes e descontextualizadas pareciam ter chegado ao fim, em decorrência das novas concepções de ensino, respaldadas nos pressupostos de um ensino indutivo, focado no aluno e baseado na contextualização e nas experiências prévias de cada discente (SAVIGNON, 2001). As quatro habilidades comunicativas são trabalhadas de forma equilibrada e interligada, pensando-se no desenvolvimento de um falante de língua inglesa que seja capaz de ler,

2 Os aprendizes podiam superar os hábitos de sua língua nativa e formar novos hábitos requeridos para falantes da língua alvo (tradução nossa). 
escrever, falar e ouvir com o mesmo nível de proficiência. Essas novas expectativas de mudança educacional, trazidas pela abordagem comunicativa não se concretizaram, segundo Almeida Filho (2001), considerando-se que apenas regras gramaticais continuam a ser ensinadas nas escolas, sem quase nenhuma referência a um ensino comunicativo e significativo da língua-alvo.

Percebe-se, dessa forma, que a preocupação com o método de ensino sempre esteve entre as prioridades do professor de língua estrangeira, neste caso, de inglês. Essas inquietações estão relacionadas à aquisição de línguas, mas desconsidera o papel social do ensino de idiomas, que pressupõe as trocas culturais e processos de (re)significação identitária, vivenciados, especialmente, por meio das atividades de leitura.

A proposta por um ensino baseado nas experiências do aluno e nas suas necessidades está presente nas atuais legislações de ensino, conforme a leitura dos Parâmetros Curriculares Nacionais (PCN) (BRASIL, 1998) e das orientações curriculares para o ensino médio (OCEM) (BRASÍLIA, 2006), que propõem um ensino de línguas voltado para a comunicação e para a formação de um aluno crítico, consciente de suas potencialidades e preparado para interagir com o mundo, uma vez que:

a aprendizagem de leitura em Língua Estrangeira pode ajudar o desenvolvimento integral do letramento do aluno. A leitura tem função primordial na escola e aprender a ler em outra língua pode colaborar no desempenho do aluno como leitor em sua língua materna (BRASIL,1998, p. 20).

Os Parâmetros Curriculares Nacionais (BRASIL,1998) destacam a importância que o texto deve ter para o ensino de uma língua estrangeira, na medida em que é recomendado que o ensino se baseie na leitura e que sejam privilegiadas as práticas que possam desenvolver o aluno como cidadão crítico no mundo globalizado, ou seja, as práticas que privilegiam o conteúdo do texto e não somente as estruturas gramaticais encontradas. É recomendado que todo o ensino tenha como ponto de partida as experiências dos alunos, e, tomando-se como base os pontos de identificação e afastamento os assuntos possam ser discutidos, uma vez que a leitura em língua estrangeira, de acordo com essa peça legislativa, também, auxilia na leitura em língua materna, por perpassar pela leitura de mundo.

Em decorrência da valorização do vínculo entre língua e cultura, o ensino de inglês pode ser analisado em termos de (re)orientação de funções sociais, inscritas no texto impresso. Falar em cultura, nesse novo contexto, é, segundo Kramsch (1998), encontrar um espaço pessoal formado por meio da interação de realidades culturais diferentes, aceitar as diversidades e trabalhá-las em sala de aula, na medida em que o contato com novas culturas e experiências fornece subsídios para se trabalhar as características de seu país, ao mesmo tempo em que fortalece o respeito pela cultura do outro. Tavares e Bezerra (2009, p. 231) compartilham do pensamento de Kramsch (1998), ao afirmarem que "o elemento cultural pode ajudar na aprendizagem de uma língua estrangeira e o aluno a respeitar os pontos de vista do outro e, ainda, a entender os aspectos linguísticos que estão, extrinsecamente ligados às questões culturais”.

Os debates sobre a inserção da cultura e do respeito às contribuições e ideias dos alunos ganhou força com o surgimento, no final do século XX, de discussões sobre a pedagogia dos multiletramentos, em que, de acordo com Cope e Kalantzis (2000), o ensino de línguas extrapola o limite das palavras e da interpretação de textos focada na decodificação de mensagens. O leitor interage com o texto, e, a partir de suas experiências prévias, apropria do texto aquilo que mais causou identificação, não mais se restringindo a encontrar respostas para as perguntas fabricadas dos autores. Trata-se, dessa forma, de um compartilhamento de experiências proporcionada pela leitura e pelas trocas culturais. 
Cope e Kalantzis (2000) defendem um trabalho textual com foco no desenvolvimento de um leitor crítico, capaz de interagir com diferentes modalidades textuais e de apropriar sentidos peculiares a cada leitura feita. A teoria dos multiletramentos, defendida pelos citados autores, destaca a importância em se privilegiar o conhecimento do aluno, os possíveis debates levantados e a construção de sentido, em detrimento de uma simples decodificação de mensagens. Esse pensamento está em consonância com as ideias da legislação vigente para o ensino de língua inglesa em ensino fundamental e médio, uma vez que os PCN, também, valorizam a língua como prática social, capaz de promover interações e sentidos negociados entre dois ou mais interlocutores.

Ao reforçar a natureza sociointeracional da linguagem, um cuidado especial deve ser dado à escolha temática, preocupação constante nos parâmetros curriculares e entre os teóricos dos multiletramentos, de modo que as escolhas dos temas passam a interessar os professores, que não mais se contentam em apresentar textos sobre assuntos descontextualizados e desconexos da realidade do corpo discente.

A temática de um texto sobre uma escova de dente não situa, imediatamente, a linguagem como um fenômeno social, já que o engajamento discursivo pela motivação temática não está patente, a menos que esse texto seja tratado em sala de aula em um contexto interacional que o faça valer como prática social [...].

Compare-se o texto sobre uma escova de dente com outros que problematizem as questões que se vivenciam no mundo social: a ética na política, as dificuldades cada vez maiores de se conseguir emprego, a importância de se utilizar práticas preventivas na vida sexual, o respeito aos direitos de todos os cidadãos sem distinção de gênero, etnia ou opção sexual etc. 0 engajamento discursivo aqui é imediato, tendo em vista as temáticas sugerirem a vida social de forma explícita (BRASIL, 1998, p. 44-45).
Essas discussões sobre os multiletramentos estão em consonância com o ramo da linguística aplicada, denominado linguística crítica, de acordo com Rajagopalan (2006). A linguística crítica tira a neutralidade do ensino e coloca no professor um potencial de desenvolvimento de um trabalho crítico com o texto. Dessa forma, por meio das discussões presenciadas, pode-se perceber uma mudança de paradigmas ou de preconcepções, uma vez que as ideias levantadas são capazes de despertar no aluno novas reações e novas identificações. 0 texto da escova de dente, conforme mencionado nos PCN, pode receber um novo redirecionamento, a partir do momento em que o professor, ciente dessas novas propostas da linguística aplicada, leva o seu aluno a refletir sobre questões que extrapolam as preocupações lexicais, ou seja, o foco não está mais na pasta de dente, e sim, nas questões culturais que envolvem hábitos e rotinas destacadas no texto e comparadas com a própria vida do aluno.

Com a difusão dessas novas perspectivas educacionais, fica clara a mudança de paradigma aqui destacada, uma vez que não há mais espaço para o simples trabalho de decodificação de texto. Com as teorias dos multiletramentos, os limites impostos pelo código linguístico são extrapolados, a favor de uma visão sociointeracional, já que passa a ser tarefa do professor, não somente trabalhar técnicas de leitura, como também oportunizar o desenvolvimento de uma leitura crítica, em que o aluno interaja com o texto, e, a partir de conhecimentos prévios, (re)significações do material lido possam existir.

Dessa forma, por meio das teorias dos multiletramentos, o ensino é entendido como o resultado de uma interação de várias modalidades, tais como, o texto escrito, imagens, vídeos, quadrinhos e etc. Além de destacar a questão multimodal, os multiletramentos, também, contemplam discussões focadas no letramento digital, ou seja, no modo pelo qual o aluno interage com as novas mídias e se apropria de forma crítica e com autoria. No letramento crítico, o discente, ao entrar em contato com o texto, independente da 
modalidade, é levado a discussões que extrapolam os conhecimentos linguísticos e focam nas questões de (re)significação e criticidade, uma vez que, o mesmo texto não gera o mesmo significado em leitores distintos (KALANTZIS; COPE, 2012).

Percebe-se, dessa forma, que o letramento crítico e a abordagem comunicativa trazem respostas importantes para que uma política de ensino de línguas possa ser instaurada de forma eficaz, já que o letramento crítico entende o texto como "local de luta, negociação e mudança” (NORTON, 2012, p. 6), dotado de forças sociopolíticas importantes para a formação crítica do aluno como cidadão. A abordagem comunicativa, por outro lado, se preocupa com a logística do ensino de línguas, trabalhando a expressão e a negociação de significados expressos por códigos linguísticos definidos, devendo esse processo de ensino aprendizagem ser o mais contextualizado e indutivo possível. Em outras palavras, "para o ensino comunicativo (EC), a língua é um instrumento de socialização; e para o letramento crítico (LC), ela é, em última análise, um instrumento de poder e de transformação social" (MATOS; VALÉRIO, 2010, p. 5).

Almeida Filho (2007), ao discorrer sobre as dimensões comunicativas no ensino de línguas, ressalta a importância em se trabalhar o ensino de língua inglesa privilegiando-se o contexto político-cultural, de modo que o professor pode ser considerado um "elemento aclarador e minimizador" de quaisquer problemas identificados na sala de aula, no que se refere a não identificação do aluno com os assuntos discutidos. Este fato, além de poder ser claramente relacionado às questões de multiletramentos aqui discutidas, reforça a importância do papel do professor em estimular discussões capazes de despertar o interesse em desvendar assuntos e mistérios nunca antes imaginados, o que faz com que as preocupações com questões de (re)significações identitárias estejam cada vez mais presentes nas aulas de língua inglesa.
É papel do professor de línguas o resgate das aulas de língua estrangeira, com o intuito de destacar que o objetivo do ensino deve incluir tanto os aspectos linguísticos quanto o caráter sociocultural da aprendizagem. Dessa forma, a competência cultural passará a ser vista como essencial no aprendizado de uma língua estrangeira e indispensável para a (re)construção de significados.

De acordo com Hall (2011), com a quebra das barreiras geográficas, presenciadas pelo fenômeno da globalização, o mundo está cada vez mais interconectado, e, como consequência, a tensão entre o global e o local acaba por gerar um verdadeiro processo de transformação de identidades. Os interesses dos alunos não estão mais circunscritos em um único espaço físico, e os discentes não são mais dependentes das informações transmitidas pelos professores. Com a facilidade advinda da internet, o local e o global se misturam, sendo, dessa forma, papel do professor de língua estrangeira o trabalho textual que envolva essas questões de (re)significação e (re)construção de identidades.

Esse fato é também confirmado por Bauman (2005), ao destacar a existência de identidades líquidas e flutuantes, disponíveis para serem utilizadas ou descartadas, como uma verdadeira "comunidade guarda-roupa". Seguindo esse ponto de vista, ao propiciar discussões críticas sobre os textos disponibilizados aos nossos alunos, estes podem "vestir" as causas que mais os atraem, tomando-as como suas, e este fato não está relacionado a nenhum processo linguístico propriamente dito.

\footnotetext{
Aprender uma língua nessa perspectiva é aprender a significar nessa nova língua e isso implica entrar em relações com outros numa busca de experiências profundas, válidas, pessoalmente relevantes, capacitadoras de novas compreensões e mobilizadora para ações subsequentes. Aprender LE assim, é crescer numa matriz de relações interativas na língua-alvo que gradualmente se desestrangeiriza para quem a aprender (ALMEIDA FILHO, 2007, p.15).
} 
Hall (2002) afirma não ser concebível uma análise de comportamentos, sejam eles educacionais ou sociais, sem que as questões culturais e identitárias sejam levadas em consideração. Nesse contexto de bus-

\section{CONSIDERAÇÕES FINAIS}

A partir das pesquisas desenvolvidas por Moita Lopes (2006), Almeida Filho (2007) e Rajagopalan (2006), é possível fazer um paralelo entre as preocupações da linguística aplicada voltadas para questões teóricas, como, por exemplo, métodos e abordagens, e as reflexões críticas originadas pelos debates sobre questões culturais, identitárias e as teorias dos multiletramentos. É importante ressaltar que não se trata de uma exclusão dos fatores linguísticos no ensino de língua inglesa, uma vez que, para que haja o processo de ensino aprendizagem em sala de aula é importante ter em mente o melhor método e/ou abordagem a ser empregado. No entanto, o ensino focado apenas nessas questões é entendido como simplista e mecânico, por desconsiderar o papel crítico e reflexivo do ensino, e ter, como alvo final, a preparação de um cidadão crítico no mundo globalizado, como defendem os PCN (BRASIL, 1998).

Tendo como base as novas perspectivas da linguística aplicada, no que se refere ao ensino dos aspectos linguísticos da língua inglesa, a abordagem comunicativa ainda parece conter um grande número de ca por (re)significação, não se justifica uma postura passiva do professor de idiomas, apoiada em métodos ultrapassados, mecânicos e focados no trabalho com listas de vocabulário.

prerrogativas válidas que justificam a sua utilização em sala de aula, em decorrência do caráter comunicativo ao qual se propõe, da valorização das experiências dos alunos e da construção de um conhecimento consolidado por meio do conjunto das quatro habilidades linguísticas: ler, falar, ouvir e escrever. Percebendo, no entanto, que este modelo é simplista, o professor de LE deve somar a estas técnicas, um conjunto de procedimentos que valorizem a leitura crítica em sala de aula, independentemente da modalidade a ser trabalhada.

Nesse cenário, é fundamental que se leve em consideração as discussões atuais sobre a cultura, a criticidade textual, as (re)construções identitárias, possibilitadas através de debates e discussões, bem como os multiletramentos, principalmente sob a forma de letramento crítico. O papel do professor em sala de aula, neste contexto, deve ser de tal forma flexível, que o permita trabalhar com o material didático extrapolando os limites linguísticos impostos, de modo a despertar no aluno a curiosidade, o interesse, a autonomia e o poder crítico reflexivo. 


\section{REFERÊNCIAS}

\author{
ALMEIDA FILHO, JOSÉ CARLOS PAES. Dimensões co- \\ municativas no ensino de línguas. Campinas: Pontes \\ editores, 2007.
}

ALMEIDA FILHO, J. C. P. O ensino de línguas no Brasil de 1978. E agora? Revista Brasileira de Linguística Aplicada, v. 1, n. 1, 2001, p. 15-29.

BRASIL. Secretaria de Educação Fundamental. Parâmetros curriculares nacionais: terceiro e quarto ciclos do ensino fundamental: língua estrangeira / Secretaria de Educação Fundamental. Brasília: MEC/ SEF, 1998.

BRASÍLIA. Ministério da Educação, Secretaria de Educação Básica. Orientações curriculares para o ensino médio: volume 1, 2006.

BAUMAN, Zigmunt. Identidade: entrevista a Benedetto Vecchi. Trad: Carlos Alberto Medeiros. Rio de Janeiro: Zahar, 2005.

COPE, B.; KALANTZIS, M. Multiliteracies: literacy learning and the design of social futures. London: Routledge, 2000

HALL, Stuart. Identidade Cultural na pós-modernidade. São Paulo: DP\&A, 2002.

KALANTZIS, M.; COPE, B. Literacies. Cambride: Cambridge University Press, 2012

KRAMSCH, Claire. Language and culture. Oxford: Oxford University Press, 1998
LARSEN-FREEMAN, Diane. Techniques and principles in language teaching. Oxford: Oxford University Press, 2000.

LOPES, Luiz Paulo da Moita (Org.). Por uma linguística aplicada indisciplinar. São Paulo: Parábola editoria, 2006.

MATTOS, Andréa Machado de Almeida; VALÉRIO, Kátia Modesto. Letramento crítico e ensino comunicativo: lacunas e interseções. RBLA, Belo Horizonte, v. 10, n. 1, 2010, p. 135-158.

NORTON, B. Critical literacy and international development. Critical Literacy: Theories and Practices, v. 1, n. 1, p. 6-15, 2007. Disponível em:

<http://www.criticalliteracy.org.uk/images/journal/ v1issue1/norton.pdf>. Acesso em: 28 maio 2012.

RAJAGOPALAN, Kanavillie. Repensar o papel da linguística aplicada. In: LOPES, Luiz Paulo da Moita (Org.). Por uma linguística aplicada indisciplinar. São Paulo: Parábola editoria, 2006.

SAVIGNON, S. J. Communicative language teaching for the twenty-first century. In: CELCE-MURCIA, M. (Ed.). Teaching English as a second or foreign language. Boston, MA: Heinle \& Heinle, 2001, p. 13-28.

TAVARES, Roseanne Rocha; BEZERRA, Selma Santos. Atividades culturais no ensino de inglês. In: GOMES, Carlos Magno (Org.). Língua e literatura: proposta de ensino. São Cristóvão: UFS, 2009. 
1 Possui graduação em Letras Inglês pela Universidade Tiradentes, é pós- graduando em Tradução de Inglês pela Universidade Gama Filho e mestrando em Letras pela Universidade Federal de Sergipe. Atualmente é proAceito em: 19 de Dezembro de 2013 fessor substituto da UFS, examinador oficial da Universidade de Cambridge e aplicador do Toefl ITP Email: rodrigobelfort13@gmail.com 